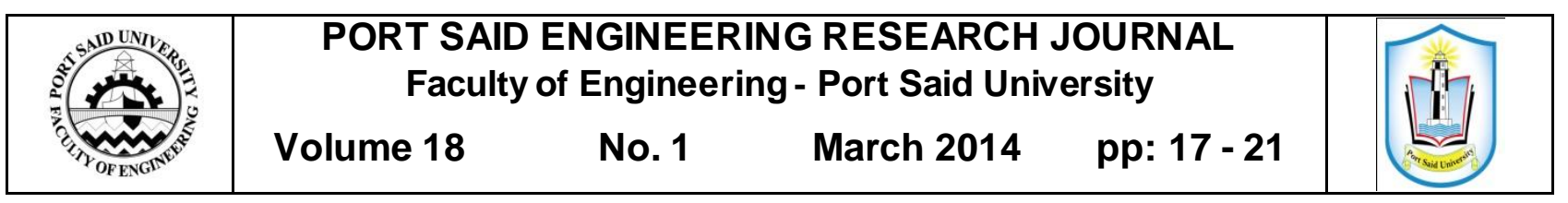

\title{
Particle Swarm Optimization-Based Pd-Controller of Dc Servo-Motor
}

\begin{abstract}
Shereen A. Elsayed ${ }^{1}$, Reda M. Ghaly ${ }^{2}$, Hossam M. Attia ${ }^{3}$, and Fahim A. Khalifa ${ }^{4}$
\section{Abstract}

This paper presents the design of a particle swarm optimization (PSO) controller for the speed of a DC servo-motor. First, a proportional-derivative particle swarm optimization (PDPSO) based controller is designed, and then compared with Signal Constraint block of Simulink Response Optimization Toolbox instead of conventional methods. The DC servo motor is modeled and simulated using simulink /MATLB environment. The obtained results ensure the superiority of PDPSO-based controller.
\end{abstract}

Keywords:DC Servo Motor, Proportional-Integral- derivative, Ziegler-Nichols method, Particle swarm optimization

\section{INTRODUCTION}

Electric motors can be classified by their functions as servomotors, gear motors, and so forth, and by their electrical configurations as (direct current) DC and (alternating current) AC motors. A further classification can be made as single phase and poly phone with synchronous and induction motors in terms of their operating principles for $\mathrm{AC}$ motors, and permanent magnet (PM) and shunt DC motors for DC's.

Although DC motors are preferred dominantly in the variable speed applications, increasing use of AC motors can be seen prior to improvements in solid state components. Servomotor is a motor use for position or speed control in closed loop control systems. The requirement from a servomotor is to turn over a wide range of speeds and also to perform position and speed instructions given DC and AC servomotors applications are seen by considering their machine structure in general.(R.No 1)

DC servo motors have been used generally at the computers, numeric control machines, industrial equipment, weapon industry, speed control of alternators, control mechanism of full automatic regulators as the first starter, optimal design of nonlinear profile for jumping robot.(R.No2), automatic solar tracker robot (R.No3), starting systems quickly and correctly. (R.No4).

In the field of control of mechanical linkages and robots, research works are mostly found on DC motors.

\footnotetext{
${ }^{I}$ Electrical Power, and Machines Department, Faculty of Industrial Education, Suez University, Suez, Egypt, E-mail:

shereenfayad@yahoo.com

${ }^{2}$ Electrical Engineering ,Faculty of Industrial Education ,Suez University ,Suez, Egypt.

${ }^{3}$ Electrical Engineering ,Faculty of Industrial Education, Suez University ,Suez, Egypt E-mail:hossam65eg@yahoo.com

${ }^{4}$ Electrical Power, and Machines Engineering Department, Faculty of Engineering, Ismailia University, Ismailia, Egypt, E-mail: foiesuez@yahoo.com
}

While some properties of DC servo motors are the same, like inertia, physical structure, shaft resonance and shaft characteristics, their electrical and physical constants are variable.

The velocity and position tolerance of servo motors which are used at the control systems are nearly the same. So they must be controlled according to the control system needs. For this aim; it has implemented proportional-integral-derivative PID and fuzzy logic system respectively to the simulation model, which has prepared at the Simulink / Matlab software package for improvement the servo motor performance. (R.No4)

Utilizing the sampling frequency affect the performance of a direct neural controller (DNC), which is applied to a DC motor speed control system is studied in . (R.No5). A DNC of self-tuning strategy is proposed as a speed regulator to keep the motor in constant without the specified reference model.

Reference (R.No6)presents the design of a robust optimal control system for a DC servo motor. The design procedure is done via a linear convex comb ination of all controllers minimizing mixed $\mathrm{H} 2 / \mathrm{H} \infty$ norm of the closed loop transfer function under parametric uncertainties and some constraints.

A neuro -fuzzy controller of the DC servo motor is designed in. (R.No7)The designed controller does not produce the overshoot such as PID controller, does not produce steady state error of fuzzy logic controller, and shortened about $10 \%$ of settling time.

A fuzzy $\log$ ic controller applied for control the position of dc servo motor is presented in. (R.No8)The position of the angle location is limited at $-\pi$ to $\pi$ radian. The results of experiment on the real plant demonstrate that the proposed fuzzy logic controller is able to sensitivity to variation of the reference position attention.Comparing the time specification performance between conventional controller and fuzzy Logic controller in position control sy stem of a DC motor is presented in. (R.No9).

Two types of controller namely PID and fuzzy logic PID controller used to control the output 
response.3.Methods of genetic algorithm (GA) and evolutionary programming (EP) are used in. (R.No10) to find the optimal PID control gain constants for the position of DC servo motor. Fuzzy logic control is added to fine tuning the gain constants.

The experimental and simulation results are conducted using PC-based interface. A design of a fuzzy control system to control the position of a DC motor is presented in (R.No11)The motor was modeled and converted to a subsystem in Simu lin k.

First, a crisp proportional-derivative (PD) controller was designed and tuned using a Simulink block instead of conventional tuning methods such as hand-tuning or Ziegler-Nichols frequency response method. Then a fuzzy proportional-derivative (FPD) controller was designed and system responses of FPDs with different defuzzification methods were investigated. A disturbance signal was also applied to the input of the control system. FPD controller succeeded to reject the disturbance signal without further tuning of the parameters where by crisp PD controller failed.

\section{DC Servo Motor Mathematical Model:}

The velocity of the DC servo motor is controlled by changing the supply voltage. According to this theory subjects 2 voltage and moment equations:

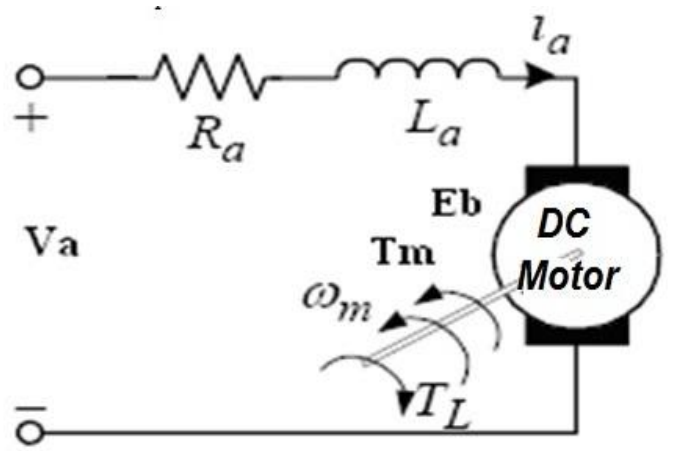

Fig.1. Armature current controlled DC servo motor equi valent circuit

$$
\begin{gathered}
V_{a}(t)=R_{a} \cdot i_{a}(t)+L_{a} \frac{d i_{a}(t)}{d t}+k_{b} \cdot w(t) \\
k_{t} i_{a}(t)=J_{m} \frac{d w(t)}{d t}+B_{m} \cdot w(t)
\end{gathered}
$$

Laplace transforms of (1) and (2) are:

$$
\begin{aligned}
& V_{a}(s)=R_{a} I_{a}(s)+L_{a} I_{a}(s) \cdot s+k_{b} \cdot w(s) \\
& K_{t} \cdot I_{a}(S)=J_{m} \cdot w(s) \cdot s+B_{m} \cdot w(s)
\end{aligned}
$$

If current is obtained from (4) and substituted in (3) we have:

$$
V_{a}=\omega(s) \frac{1}{k_{b}}\left[L_{a} J_{m} s^{2}+\left(R_{a} J_{m}+L_{a} B_{m}\right)+\left(R_{a} B_{m}+\right.\right.
$$

KbKt](5)

Then the relation between rotor shaft speed and applied armature voltage is represented by transfer function:

$\frac{W(s)}{V_{a}(s)}$
$=\frac{K_{t}}{L_{a} J_{m} \cdot S^{2}+\left(R_{a} \cdot J_{m}+L_{a} \cdot B_{m}\right) \cdot s+\left(R_{a} \cdot B_{m}+K_{b} K_{t}\right)}$

The relation between position and speed is:

$\theta(s)=\frac{\omega(s)}{s}$

Then the transfer function between shaft position and armature voltage at no-load is:

$\frac{\theta(\mathrm{s})}{\mathrm{V}_{\mathrm{a}}(\mathrm{s})}$

$=\frac{K_{t}}{\left[L_{a} J_{m} \cdot S^{2}+\left(R_{a} \cdot J_{m}+L_{a} \cdot B_{m}\right) \cdot s+\left(R_{a} \cdot B_{m}+K_{b} K_{t}\right)\right] s}$

Figure 2 shows the DC motor model built in Simulink. Motor model was converted to 2-in and 2-out subsystem. Input ports are armature voltage (Va) and load torque ( $T$ load) and the output ports are angular speed in (w) and position (theta). (R. No11)

Where:

$V_{\alpha}=$ armature voltage $(\mathrm{V}), R_{\alpha}=$ armature resistance $(\Omega)$

$L_{a}=$ armature inductance $(\mathrm{H}), I_{\alpha}=\operatorname{armature}$ cu rrent $(\mathrm{A})$

$E_{b}=$ back emf $(\mathrm{V}), \omega=$ angular speed $(\mathrm{rad} / \mathrm{s})$

$T_{m}=$ motor torque $(\mathrm{N}-\mathrm{m}), \Theta=$ angular position of

rotor shaft $(\mathrm{rad}), l_{m}=$ rotor inertia $\left(\mathrm{kg}-\mathrm{m}^{2}\right)$

$B_{m}=$ viscous friction $(\mathrm{N}-\mathrm{ms} / \mathrm{rad})$

$K_{\mathrm{t}}=$ torque constant $(\mathrm{N}-\mathrm{m} / \mathrm{A}), K_{b}=$ back emf constant (vs. /rad)

,Let us combine the upper equations together: 


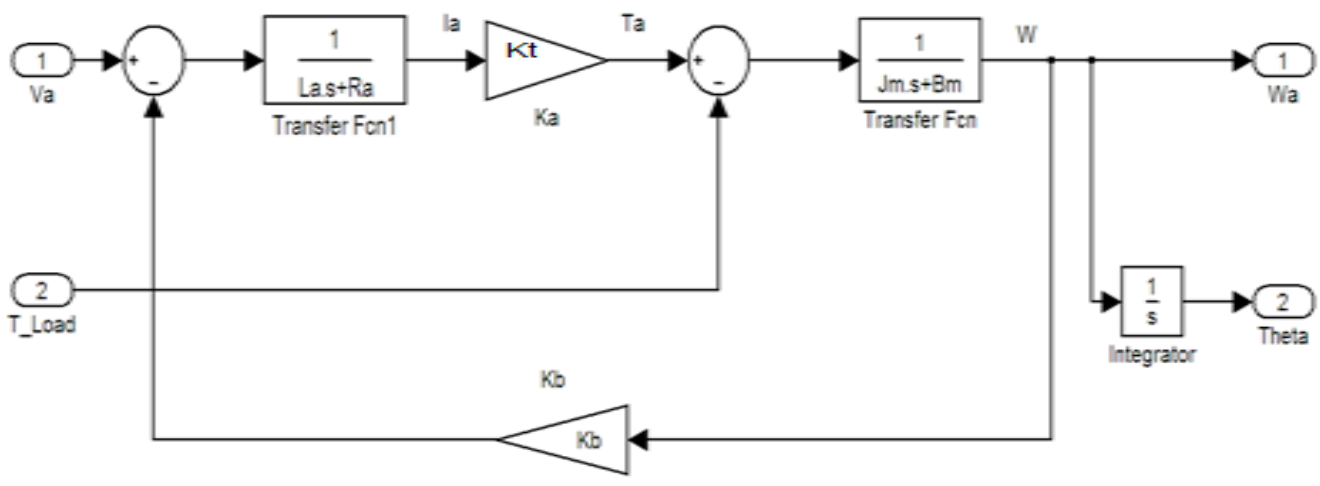

Fig 2: The DC servo-motor simulink model

\section{3 - BASIC METHOD OF PSO:}

Kennedy and Eberhart. (R.No12) developed a PSO concept the PSO is basically developed through simulation of bird flocking in two-dimensional space. The position of each agent is represented by XY axis position and also the velocity is expressed by $v_{x}$ and $v_{y}$ in the $x$ and $y$ direction respectively. Modification of the agent position is realized by the position and velocity information. Bird flocking optimizes a certain objective function. Each agent knows its best value so far (pbest), and its xy position. This information is analogous to the personal experience of each agent. Moreover, each agent knows the best value so far in the group (gbest) among the obtained pbests.

This information is analogous to knowledge of how other agents in the group have performed. Namely, each agent tries to modify its position. Position modification can be represented by the concept of velocity. The velocity of each agent can be modified by the following equation (12)

$\mathrm{v}_{\mathrm{i}}^{\mathrm{k}+1}=\mathrm{k}\left[\mathrm{v}_{\mathrm{i}}^{\mathrm{k}}+\mathrm{v}_{\mathrm{i}}^{\mathrm{k}}+\mathrm{c}_{1} \operatorname{rand}_{1} *\left(\right.\right.$ pbest $\left._{\mathrm{i}}-\mathrm{s}_{\mathrm{i}}^{\mathrm{k}}\right)$

$+\mathrm{c}_{2}$ rand ${ }_{2} *\left(\right.$ gbest $\left.\left.-\mathrm{s}_{\mathrm{i}} \mathrm{k}^{\mathrm{k}}\right)\right]$

Where,

$\mathrm{K}=$ the constriction factor $=\frac{2}{\left|2-\varphi-\sqrt{\varphi^{2}}-4 \varphi\right|}$, and $\varphi=c_{1}+c_{2}, \varphi>4$

$v_{i}^{k}:$ velocity of agent $\mathrm{i}$ at iteration $\mathrm{k}$,

$c_{i}$ : weighting factor,

rand $d_{i}$ : rando $m$ nu mber between 0 and 1 ,

$s_{i}{ }^{k}$ ₹ current position of agent $\mathrm{i}$ at iteration $\mathrm{k}$,

pbest $t_{i}$ :pbest of agent i,

gbest : gbest of the group.

The current position (searching point in the solution space) can be modified by the following equation: $s_{i}^{k+1}=s_{i}^{k}+v_{i}^{k+1}$

\section{DESIGN of PDPSO-BASED SERVO- MOTOR CONTROLLER:}

\subsection{DC servo-motor model with PD}

In the DC servo-motor model shown in Fig. 2, the PD controller is added as shown in Fig. 3 with the following structure:

$G_{C}(s)=k_{p}+k_{d} s$

where

$k_{p}=$ proportional control gain, \& $k_{d}=$ differential control gain.

The dynamic equations of this model can be written in the state-space form as

$\dot{x}(t)=A x(t)+B u(t)+F \Delta P_{d}(t)$

The system $A$ matrix after adding the PD signals becomes

$A=\left[\begin{array}{ccc}-\frac{R_{a}}{L_{a}} & -\frac{K_{b}+K_{d}}{L_{a}} & -\frac{K_{p}}{L_{a}} \\ \frac{K_{a}}{J_{m}} & -\frac{B_{m}}{J_{m}} & 0 \\ 0 & 1 & 0\end{array}\right]$

The DC servo-motor simulink model including the PD controller is shown in fig 4 .

\subsection{PDPSO-ba sed controller}

To increase the system damping, the eigen value-based objective function is considered as follows:

$J=\max \left\{\right.$ Real $\left(\lambda_{\mathrm{i}}\right): \lambda_{\mathrm{i}} \in$ electromechanical modes $\}$ (14) 
where Real $\left(\lambda_{i}\right)$ is the real part of the $i^{\text {th }}$ electromechanical mode eigenvalue of the $A$ matrix. In the optimization process, it is aimed to minimize $J$ in order to shift the poorly damped eigenvalue to the left in s-plane.

The proposed approach employs PSO to solve this optimization problem and search for an optimal set of PD gains. MATLAB files for the PSO have been developed in (R.No13).It is modified and employed to get the optimal values of the PID gains. In addition to the main BFA program, additional programs are designed to get the state-space representation of the system. The obtained values of the PD gains using PSO are: $k_{p}=$ 1.9547,

$k_{d}=2.5706$.

\section{PERFORMANCE EVALUATION}

In order to provide the efficiency of the proposed PDbased PSO controller, it is evaluated through a comparison of its response with that of the PD-based signal constrained block, which introduced in (R.No11).

\subsection{PD-ba sed Signal Constrained block [11]}

A PD controller was designed to control the DC motor. Control signal of a PD controller is as follows:

$u(n)=K_{p}\left(e(n)+T_{D} \frac{e(n)-e(n-1)}{T_{s}}\right)$

Controller parameters were tuned using Signal Constraint block of Simulink Response Optimization Toolbox instead of conventional methods.

Performance criteria were specified as:

Rise time $\left(t_{r}\right) \leq 1 s$,

Settling time $\left(t_{s}\right) \leq 2 s$

Maximum overshoot $\left(M_{p}\right) \leq 10 \%$,

Steady state error (e) $\leq 1 \%$

The objective in control system design is to find a control signal that satisfies the performance requirements.

The obtained PD gains are as follows: $K_{p}=$ $5, \quad K_{D}=0.4156$.

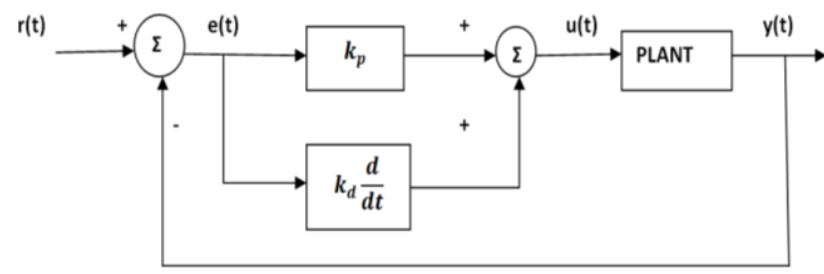

Fig. 3:. PD control system.

\section{SIMULATION RESULTS}

The simulation results are illustrated in two figures (5\& 6). Each figure represents a controller showing the responses of the PD controllers. Fig 5 shows the PD control system designed in MATLAB/Simulink where controller coefficients were adjusted using the Signal Constraint block

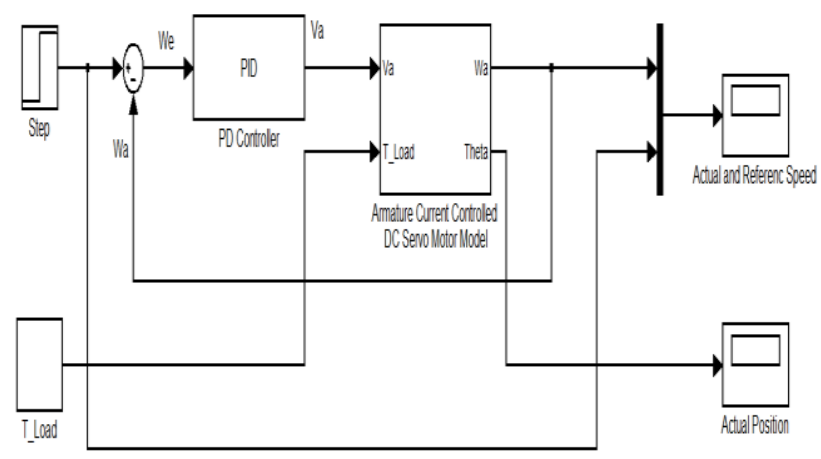

Fig 4. DC servo-motor Simulink model with PD control system

In Fig 6 shows the PDPSO-based controller response. The values are finding parameters by PSO controller response where were $\mathrm{kp}=1.9547, \mathrm{kd}=2.5706$ and note that there is no Overshoot and note that the curve up to the real speed is better than Fig 5 .

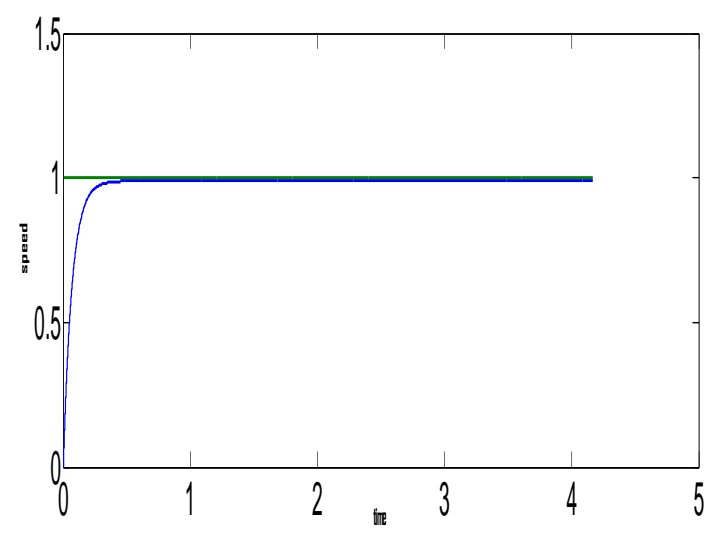

Fig 5. Signal Constrained bl ock-Based PD controller response

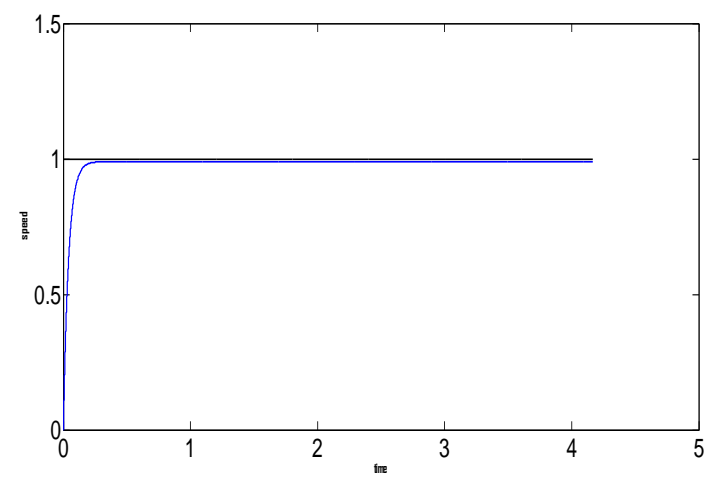

Fig 6 : PSO-Based PD controller response at no load.

Table 1 shows the values of the performance criteria obtained with the adjusted controller parameters. 
Table 1: Parameters of PID ControlledSystems for Different Values Of Required Response

\begin{tabular}{|l|l|l|}
\hline No.fig & Actual Response & $\begin{array}{l}\text { Value of PID } \\
\text { Controller }\end{array}$ \\
\hline 5 & Percent Overshoot $=0$ & $\mathrm{Kp}=5$ \\
& Settling Time $=0.8 \mathrm{sec}$ & $\mathrm{Kd}=0.4156$ \\
& Peak Time $=0$ & \\
\hline 6 & Percent Overshoot $=0$ & $\mathrm{Kp}=1.9547$ \\
& Settling Time $=0.25 \mathrm{sec}$ & $\mathrm{Kd}=2.5706$ \\
& Peak Time $=0$ & \\
\hline
\end{tabular}

\section{7 .CONCLUSION:}

The design of a PDPSO-based controller for the speed of a DC servo-motor is presented in this work. The DC servo-motor with the proposed controller is compared with the PD- based Signal Constrained block of the MATLAB/Simulink. The proposed PDPSO- based controller has much faster response than that of the other controller. However the PDPSO is much better in terms of the peak value and the settling time than the PD-based Signal Constrained block.

\section{8 .APPENDIX}

$\begin{array}{llc}\begin{array}{l}\text { DC Servo Motor Specifications:- } \\ \text { Rated power }\end{array} & 3.70 & \mathrm{~K} \mathrm{w} \\ \text { Rated voltage } & 240 & \mathrm{~V} \\ \text { Armature resistance (Ra) } & 11.2 & \Omega \\ \text { Armature inductance (La) } & 0.1215 & \mathrm{H} \\ \text { Motor Moment of Inertia (J) } & 0.02215 & \mathrm{~kg}-\mathrm{m}^{2} \\ \text { Damping coefficient (B) } & 0.002953 & \mathrm{Nms} / \mathrm{rad} \\ \text { Torque constant Kt } & 1.28 & \mathrm{Nm} / \mathrm{A} \\ \text { Back emf constant } \mathrm{Kb} & 1.28 & \mathrm{Vs} / \mathrm{rad}\end{array}$

\section{REFERENCES}

[1] L. Canaan Dülger and Ali Kireçci, "Motion Control and Implementation for an AC Servomotor System" Modelling and Simulation in Engineering, vol. 2007, Article ID 50586, 6 pages, 2007.

[2] M. Okada, and Y. Takeda, "Optimal Design of Nonlinear profile of Gear Ratio using Non-circuilar Gear for Jumping Robot" IEEE International conference on robotics and automation, pp. 19581963, Saint Paul, Minnesota, May 14-18,USA2012.

[3] A.B. Afarulrazi, W.M. Utomo, K.L. Liew, and M. Zarafi, "Solar Tracker Robot Using Mic rocontroller" International conference on business, engineering and industrial applications (ICBEIA), pp. 47-50, 5-7 June, Kuala Lu mpur, Malaysia 2011.

[4] Temiz I. and Akar M.," Motion Controller Design for the Speed Control of DC Servo Motor",
International Journal Of Applied Mathem APPLIED MATHEMATICS AND INFORMATICS, Issue 4, Volu me 1, 2007.

[5] M. Chu, Y. Chen, Y. Kang, and Z. Chen, "The Research of Sampling Frequency for A Dc Servo Motor Speed Control System Based on Neural Networks" 6th International conference on natural computation (ICNC), pp. 1401-1405, 10-12 Aug, TBD, China2010.

[6] Y. Aydin, "Design of Robust Optimal Linear Parameter Varying (LPV) Controller for DC Servo Motor" XIX International conference on electrical machines (ICEM), pp. 1-6, Rome, Italy 2010.

[7] Y. Kang, L. Kim," Design of Neuro-Fuzzy Controller for the Speed Control of a DC Servo Motor" 5th International conference on electrical machines and systems, pp. 731-734, Vol. 2, Seoul, Korea 2001.

[8] N. Khongkoom, A. Kanchanathep, S. Nopnakeepong, S. Tanuthong, S. Tunyasrirut, and R. Kagawa, "Control of the Position DC Servo Motor by Fuzzy Logic" pp. 354-357, vol. 3, TENCON, Kuala Lu mpur, Malaysia 2000.

[9] G.Sudhal , DR.R.anta2 , "Performance Based Comparison Between Various Z-N Tuninng PID And Fuzzy Logic PID Controller In Position Control System Of DC Motor", International Journal on Soft Computing (IJSC) Vol.3, No.3, August 2012.

[10] M.Hung, H.Yau, P. Chen, and Y. Su, "Intelligent Control Design and Implementation of DC Servo Motor" 2010 International symposium on computer, communication, control and automation, pp. 369-372 Taiwan 2010.

[11] Manafeddin Namazov," DC motor position control using fuzzy proportional-derivative controllers with different defuzzification methods", Turkish Journal of Fuzzy Systems Vol.1, No.1, pp. 36-54, 2010.

[12] J. Kennedy and R. Eberhart, "Swarm Intelligence", Book, Morgan Kaufmann Publishers, 2001.

[13] B. Birge, "PSOt - a particle swarm optimization toolbox for use with Matlab" Proceedings of the IEEE Swarm Intelligence Sy mposium, pp. 182-186, April 2003.

[14] Wan Robaah Binti W Ahmed," A DC Motor Controller Using PID Algorithm Implementation On PIC", November 2008.

[15] Bindu R.1, Mini K. Namboothiripad2, "Tuning of PID Controller for DC Servo Motor using Genetic Algorithm" International Journal of Emerging Technology and Advanced Engineering, Volume 2, Issue $\quad 3, \quad$ March 2012. 